\title{
The dynamic behaviour of the mammoth in the Spanish fortress, L'Aquila, Italy
}

\author{
Filippo Casarin ${ }^{1, a}$, Emma Beccaro ${ }^{1}$, Matteo Fattoretto ${ }^{1}$, Paolo Girardello ${ }^{1}$, Mauro Caldon ${ }^{2}$ \\ ${ }^{1}$ EXPIN srl, spin-off of the University of Padova, Italy \\ ${ }^{2}$ Department of Civil, Architectural and Envirnomental Engineering, University of Padova, Italy
}

\begin{abstract}
The fossil remains of a "Mammuthus Meridionalis" were found the $25^{\text {th }}$ of march 1954 in a lime quarry close to the city of L'Aquila. The Mammoth skeleton was soon "reconstructed" on a forged iron frame, and it was located in one of the main halls of the Spanish fortress in L'Aquila. A comprehensive restoration was recently completed (2013-2015), also considering the study of the adequacy of the supporting frame, which demonstrated to survive the relevant 2009 l'Aquila earthquake. After a laser-scanner survey, allowing to build a very detailed Finite Element model, Operational Modal Analysis was employed in order to obtain the dynamic identification of the structure. Results of the experimental activities explained the capacity of the structure to bear the 2009 main shock, since the natural frequencies demonstrated to be quite reduced. The structure acted as a "natural" seismic device, avoiding to reach its Ultimate Limit State however paying the toll of relevant displacements. The seismic motion caused several cracks at the edge of the bones, indicating the non-fulfilment of the ALS (damage Limit State of Artistic contents). A proposal for seismic isolation and redesign of the supporting frame was then discussed. The paper illustrates the scientific activities assisting the restoration intervention, entailing a multidisciplinary approach, in the fields of restoration, palaeontology and seismic engineering.
\end{abstract}

\section{Introduction}

In the framework of the restoration works of the Mammuthus Meridionalis in L'Aquila, Italy, a multidisciplinary team composed by specialists in different fields (palaeontology, restoration, earth science, engineering) was created in order to study the fossil skeleton of the mammoth from different perspectives.

A relevant part of the activities concerned the study of the metallic supporting frame of the mammoth, and in particular, its structural stability, being located in a seismic prone area, and having survived the very strong 2009 L'Aquila earthquake with caused severe damage in the city and in the surrounding areas.

A dedicated web page [1] has been created for providing information to the public on the activities carried out.

\section{The restoration works}

The restoration activities started in late October 2013, with the preliminary cleaning of the bone elements, removing the thick layer of dirt accumulated in the years, with the mapping of the conservation status and the execution of the first diagnostic tests.

At a distance of about twenty-three years from the last restoration intervention, the skeleton presented many cracks along the most fragile bones, in close proximity to the contact points between the metal structure and the skeleton, and between the bones, this most likely caused or worsened by the 2009 earthquake.

After the preliminary cleaning and the partial removal of the painting, which covered the reconstructed parts, to proceed with the restoration it was necessary to disassemble the skeleton. This operation was divided into three phases: the first involved the removal of the jaw, the ribs and the vertebrae, the second the shoulder blades and the limbs, the third and the most delicate, the skull, the pelvis and the sacrum.

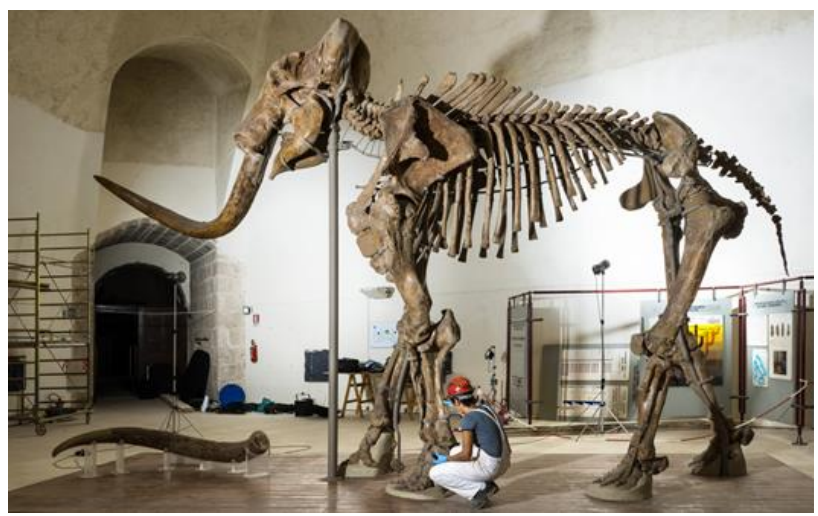

Figure 1. the Mammuthus Meridionalis in L'Aquila during the restoration works

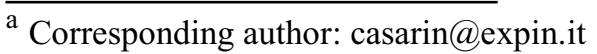




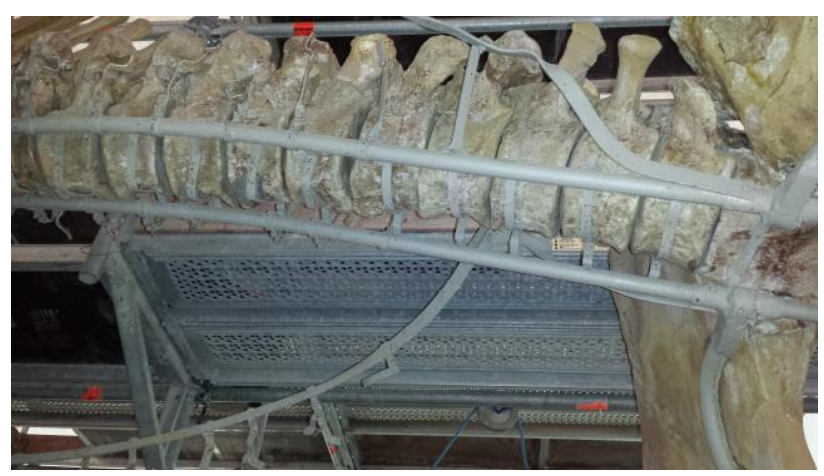

Figure 2. detail of the supporting iron frame of the mammoth bones

The large bones needed, in order to be cautiously removed and because of their size and fragility, special supports made on purpose. The bones - after the photographic documentation and cataloguing - were located in shelves and tables to be individually restored.

The state of conservation of the skeleton differed by the type of bone: the vertebrae, mainly consisting in spongy bone tissue, are more fragile and presented numerous fractures, possibly induced by the earthquake. The legs, composed by a more compact bone tissue and in the past having undergone invasive but very effective treatments, presented quite a good condition.

An acrylic resin, diluted in butyl acetate, compatible with products already used in the previous restorations, but with a better molecular characteristic, was diffusedly employed for the restoration. The consolidation took place with the immersion, for a time varying from two to three hours, in tanks containing the fixing solution. The solution penetrated into the spongy tissue expelling the contained air. At the end of this process, the bones were extracted from the tanks and left to dry in an aired place for about 10-20 days. For more fragile and degraded bones the consolidation involved also the improvement of the structural bonding with the detached parts and the infiltration of resins through injections with syringes in the cracks.

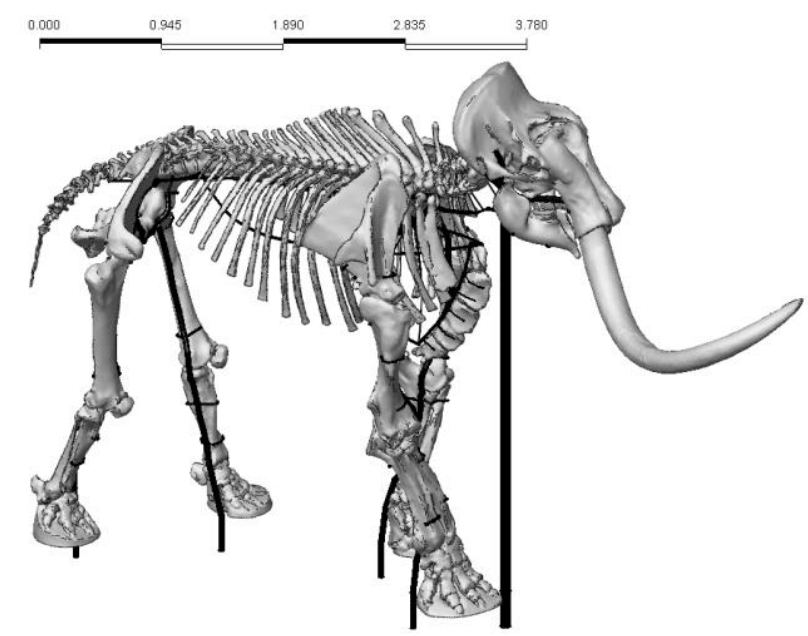

Figure 3. the Finite Element model of the Mammuthus Meridionalis
The bearing structure is made by an iron frame, moulded in the 50's around the bones by a local blacksmith, and can be roughly divided into "primary" (legs supports, hollow pipes supporting the spine, connecting rings between the legs supports and the hollow pipes, a pole supporting the skull) and "secondary" elements (hooks connecting the bones to the primary elements). The bones are connected to the frame by contact or are constrained to it by hooks. Some bones of the skeleton are supported by minor metal elements.

the on site survey showed the great deformability (next to conditions of lability) of the metal frame. It was in fact possible to move by hand the whole supporting frame in the transverse direction of several centimetres, resulting this to be the predominant deform shape in the dynamic behaviour.

\section{The FE model of the mammoth}

The global model of the mammoth was implemented by a commercial Finite Elements software [2], using the 3-D geometric model of the mammoth obtained with the laser scanner technique.

The laser scanner provided a noisy set of "shell" elements, externally defining the overall geometry, subsequently converted into 2-D plate Finite Elements, by automatically refining the original mesh. It was then necessary to transform the plate elements in threedimensional tetrahedral solid elements by filling the cavities within the model, obtaining then a fully 3-D 5 million elements solid model (Figure 3).

In a second phase, in order to simplify the geometry of the bearing elements for structural verification purposes, the steel frame was manually created by using beam elements. The model of the frame results as an independent structure from the mammoth, linked to this last in the exact correspondence of the physical connections between frame and bones (Figure 4).

This approximation was also adopted in order to consistently transmit the entire weight of the bones to the frame: the three-dimensional model of the mammoth, deriving from the laser scanner survey, can not consider the full detachments that actually exist between the various bones.

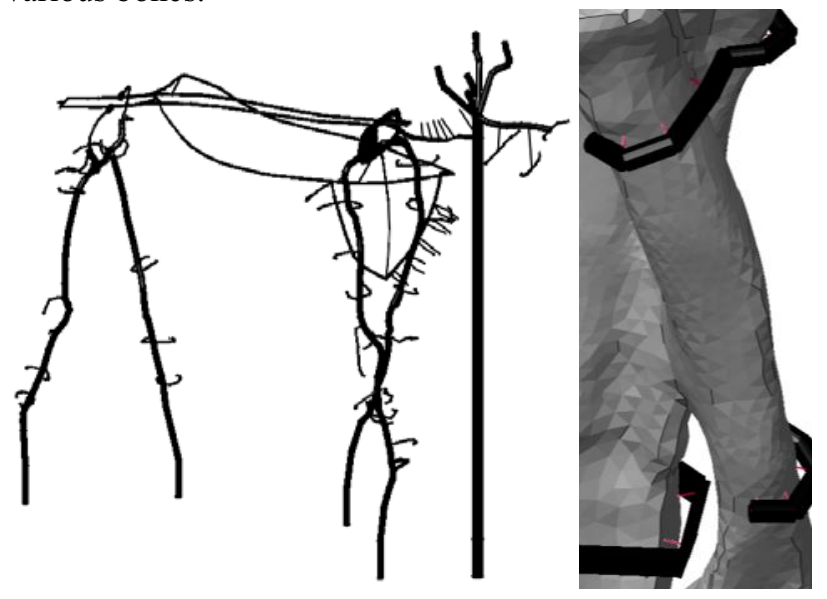

Figure 4. the FE model of the supporting metallic structure of the mammoth 
The cross-sections of the frame beam elements were assigned on the basis of the measurements made on site, resulting in the following dimensions:

- Main structure of the legs, pelvis and skull: 25x50 mm solid rectangular section;

- Structure of the basin: 20x34 mm half round;

- Hooks: 15x35 mm half round;

- Support pole of the skull: hollow tube, external diam. $87.5 \mathrm{~mm}$, thickness $6 \mathrm{~mm}$;

\subsection{Material properties}

The knowledge of the weight together with the exact volume of the skull indicated an overall mass density of $1 ' 300 \mathrm{~kg} / \mathrm{m}^{3}$ for the bones. A very reduced modulus of elasticity, equal to $2.58 \mathrm{E}+08 \mathrm{~N} / \mathrm{m}^{2}$ was employed for the skeleton, in order to simulate in a "smeared" manner the gaps between the different bones, invisible by the FE simulation, leaving the task of supporting the bones to the sole iron frame.

A steel type S235 was used for the steel structure of the frame:

- mass density: 7'850 kg/m³

- Modulus of elasticity: $2.06 \mathrm{E}+11 \mathrm{~N} / \mathrm{m}^{2}$.

\section{2 the FE model calibration}

The FE model was calibrated on the results of the dynamic tests. The dynamic identification tests have clearly identified the first two frequencies $(0.56 \mathrm{~Hz}$, $0.75 \mathrm{~Hz}$, see chapter 4), representing the first global vibration modes in the transverse and longitudinal directions.

Table 1. FE model calibration based on dynamic identification

\begin{tabular}{|c|c|c|c|}
\hline Mode shape & $\begin{array}{c}\text { Rotational } \\
\text { stiffness }\end{array}$ & $\begin{array}{c}\text { FE freq } \\
(\mathrm{Hz})\end{array}$ & $\begin{array}{c}\text { Error } \\
(\%)\end{array}$ \\
\hline $1^{\text {st }}$ mode & \multirow{2}{*}{$\begin{array}{c}100 \% \\
\text { (clamped) }\end{array}$} & 0.72 & 33.1 \\
\hline $2^{\text {nd }}$ mode & & 0.94 & 27.7 \\
\hline $1^{\text {st }}$ mode & \multirow{2}{*}{$50 \%$} & 0.69 & 28.4 \\
\hline $2^{\text {nd }}$ mode & & 0.91 & 24.6 \\
\hline $1^{\text {st }}$ mode & \multirow{2}{*}{$30 \%$} & 0.66 & 23.2 \\
\hline $2^{\text {nd }}$ mode & & 0.89 & 21.2 \\
\hline $1^{\text {st }}$ mode & \multirow{2}{*}{$8 \%$} & 0.55 & 1.8 \\
\hline $2^{\text {nd }}$ mode & & 0.79 & 8.1 \\
\hline $1^{\text {st }}$ mode & \multirow{2}{*}{$\begin{array}{c}0 \% \\
\text { (hinged) }\end{array}$} & 0.29 & 46.9 \\
\hline $2^{\text {nd }}$ mode & & 0.63 & 14.3 \\
\hline
\end{tabular}

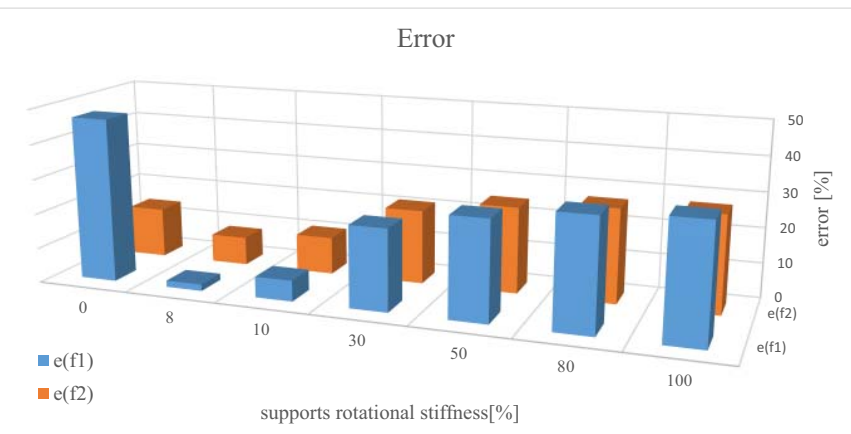

Figure 5. FE versus experimental frequencies error, based on the rotational stiffness of the supports
The unknown parameter was considered to be the rotational stiffness of the constraints (paws and pole base), that was gradually reduced in order to minimize the differences between the frequencies obtained experimentally and those supplied by the FE modal analysis. As a first value the clamped condition at the base was assigned (100\% of rotational stiffness). Subsequently, varying the percentage with steps of 20 $30 \%$ until to the hinged conditions $(0 \%$ rotational stiffness), the error (e) on the first frequencies identified was plotted.

$$
\mathrm{e}=(\mathrm{fm}-\mathrm{fs}) / \mathrm{fs} \cdot 100
$$

in which:

$\mathrm{fm}$ is the frequency obtained from the model

$f s$ is the frequency obtained from the dynamic tests

The rotational stiffness value of $8 \%$ was found to minimize the error between the first two eigenvalues, and was then employed for the seismic response analyses.

In Table 1 and Figure 5 the FE modal frequencies of the model and relative errors versus the rotational stiffness of the constraints are shown, considering as exact values those obtained by the experimental dynamic identification.

\section{3. structural analysis results}

\subsubsection{Linear static analysis}

The linear static analysis was carried out in order to assess the stress level in the elements of the metal frame. The only force considered for this analysis was the selfweight.

Analysing the axial stresses of the beam elements of the frame it emerges that the most stressed elements are the vertical supports of the structure ("legs" and skull pole) transmitting to ground the entire weight of the skeleton. It was noted that the only self weight generally induces limited forces on the slender frame elements, with maximum stresses - measured in the pole below the skull - of approximately $40 \mathrm{~N} / \mathrm{mm}^{2}$. The axial forces on the frame elements are presented in Figure 6.



Figure 6. axial forces on the iron element of the frame, selfweight analysis 
It was possible to numerically estimate the overall weight of the bones $(17,63 \mathrm{kN})$, once subtracted the weight of the iron frame $(4,13 \mathrm{kN})$. No relevant stresses localize in the bone elements of the skeleton, with concentration - however limited - in the contact points between these and the metallic supports.

\subsubsection{Modal analysis}

The natural frequency analysis indicate the presence of well-defined global modes, since just the first five vibration modes are related to a participating mass of $84.5 \%$ in the $\mathrm{x}$ direction or the transverse direction, and $82.9 \%$ in the $\mathrm{y}$ direction, i.e. in the longitudinal direction (Table 2, Figure 7).

Table 2. FE model eigenvalues, natural frequency analysis

\begin{tabular}{|c|c|c|c|}
\hline Mode nr. & $\begin{array}{c}\text { Frequency } \\
(\mathbf{H z})\end{array}$ & $\begin{array}{c}\text { Mass X } \\
\mathbf{( \% )}\end{array}$ & $\begin{array}{c}\text { Mass Y } \\
(\mathbf{\%})\end{array}$ \\
\hline $1^{\text {st }}$ mode & 0.547 & 84.2 & 0.76 \\
\hline $2^{\text {nd }}$ mode & 0.793 & 0.55 & 35.56 \\
\hline $3^{\text {rd }}$ mode & 1.036 & 0.20 & 46.56 \\
\hline $4^{\text {th }}$ mode & 2.060 & 0.01 & 0.00 \\
\hline $5^{\text {th }}$ mode & 2.399 & 0.00 & 0.05 \\
\hline
\end{tabular}


Figure 7. mode shapes: first "transverse" (above) and second "longitudinal/torsional" (below) modes

\subsubsection{Spectral response analysis}

The spectral analysis was carried out using two 5\% damped response spectra derived from the main shock acceleration record measured at the INGV (National Institute of Geophysics and Volcanology) AQU seismic station, at a very close distance from the Spanish Fortress in L'Aquila, recorded the 6 of April 2009 [3].


Figure 8. elastic response spectra derived from $6^{\text {th }}$ of April 2009 main shock, AQU station: N-S (blue) and E-W (red)
The two spectra (Figure 8), corresponding to the North - South (y direction related to the FE model) and East-West directions, have been combined with the action of the self-weight in order to simulate the earthquake of April 6, 2009 and to assess the seismic response of the frame.

The reduced dynamic frequency values of the structure - indicating a relevant deformability - allowed the mammoth skeleton to avoid the main energy content of the earthquake, which contained peaks, in the response spectrum of approximately $0,8 \mathrm{~g}$ at the frequency of 10 $\mathrm{Hz}$ and a measured PGA of $0,31 \mathrm{~g}$.

Therefore, the seismic analysis indicates that the steel elements of the legs are satisfactorily checked for resistance, given the relatively limited inertial forces agents. However, some of the structural elements of the frame do not comply with the prescriptions of the Italian national standard [4], the forces induced by the earthquake overpassing the Ultimate Limit State, for a combination of bending and axial loads at the base of the pole supporting the skull (Figure 9a).
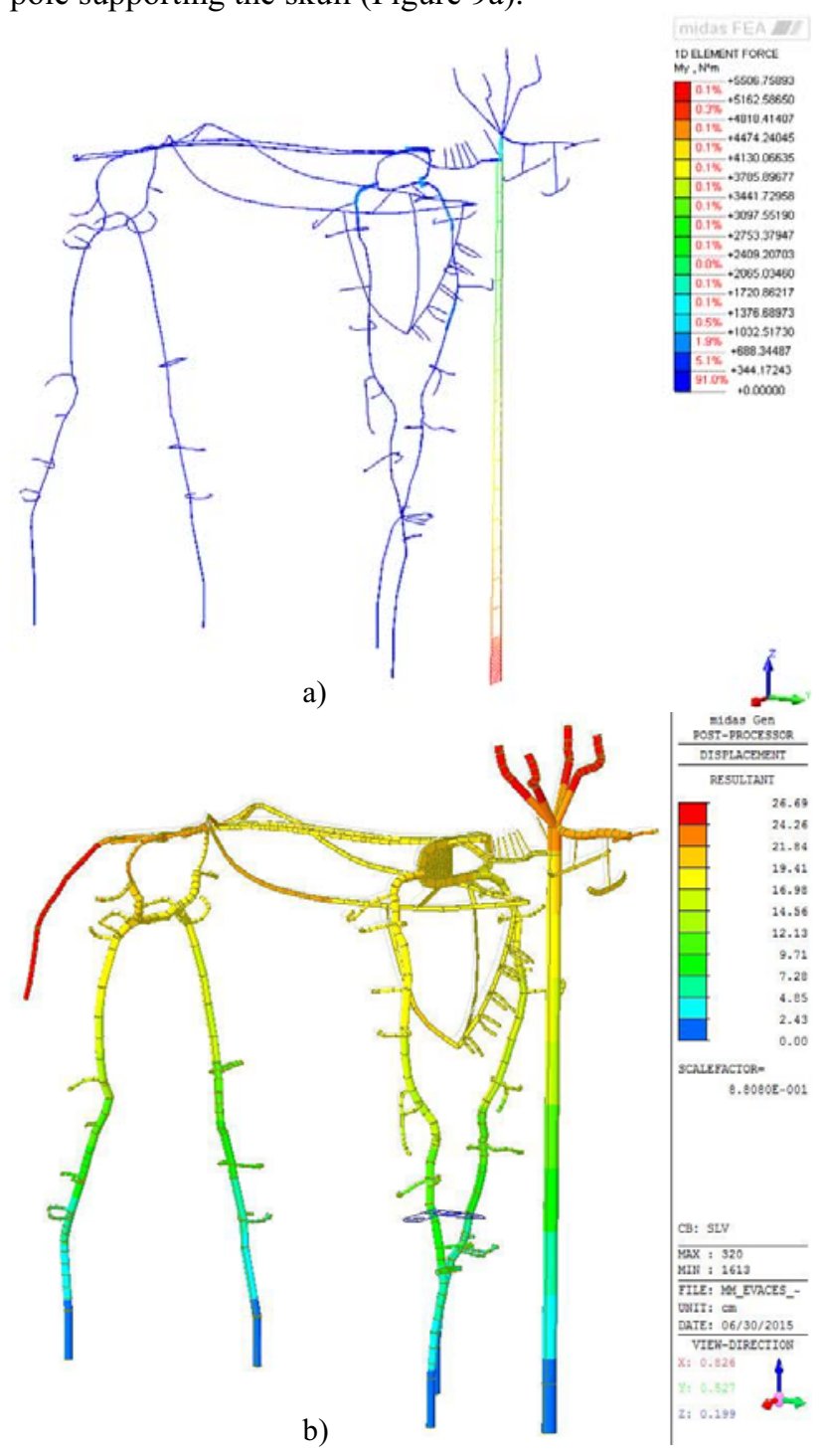

Figure 9. $6^{\text {th }}$ of april 2009 earthquake effects on the supporting frame: a) bending in transverse direction; b) XYZ displacements 
Moreover, the very relevant seismic displacements of the frame and skeleton emerged from the analysis (Figure $9 b$ ), in the range of $0,2 \mathrm{~m}$ or more of transversal deflection, and indirectly witnessed following the 2009 earthquake (significant "rubbing" between the bones, cracks of these in correspondence of the contact points, bones found on the floor...), are incompatible with the correct conservation needs of the fossil.

\section{The dynamic identification of the mammoth}

Tests to identify the dynamic response of the Mammuthus Meridionalis were carried out the day 30 October 2013, and following the restoration activities, the day 2-3 April, 2015. The activities carried out consisted in the measurement of vibrations in several points of the structure, in order to identify the natural frequencies and the associated mode shapes. The analysis was based on the study of the system's response to an unknown excitation, consisting in the ambient vibration (Operational Modal Analysis).

Four/five acquisition setups were employed for the dynamic identification, with 8 to 12 seismic high resolution piezoelectric accelerometers fixed at different levels of the frame in correspondence of the base, the knee, the joint paw / body, spine and skull (Figure 10).
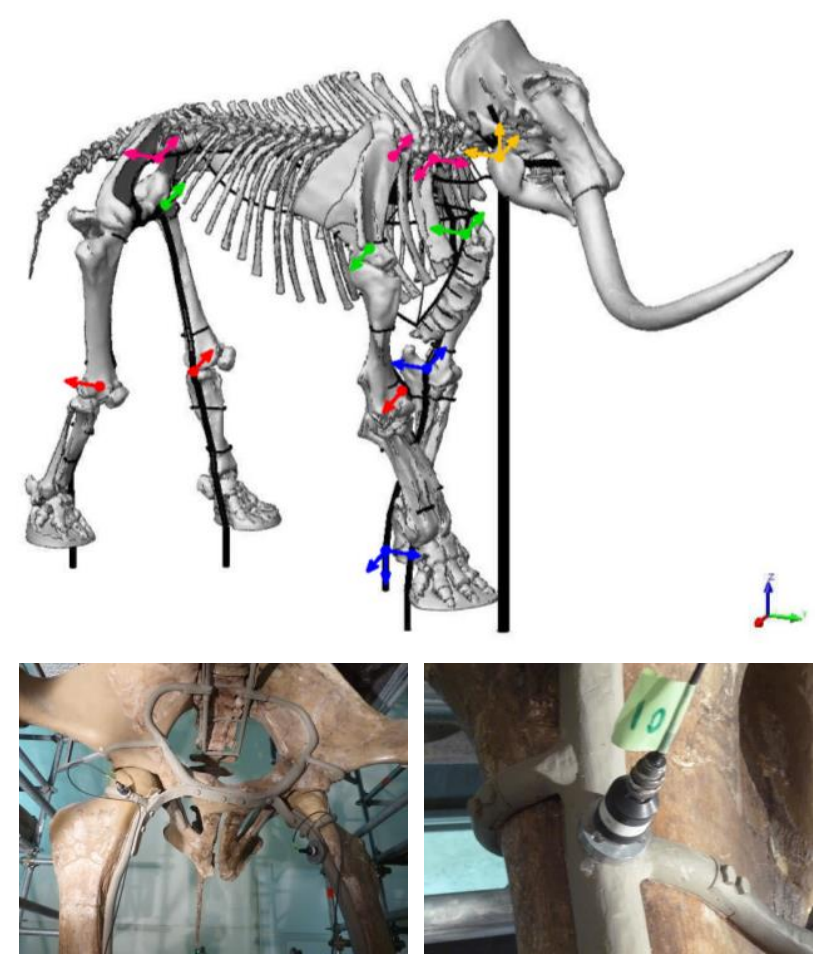

Figure 10. points of application and view of some of the acceleration sensors

In 2013, four configuration setups for a total of 21 points of acquisition were employed. For the first setup eight sensors were used, three of which were steadily fixed to the base in three orthogonal directions (X, Y, and $\mathrm{Z}$, channels 1, 2 and 3), considered as reference for all measurements. For each setup 3 records were stored (65'536 points each) with a sampling frequency equal to 100 SPS, for a total duration of about 10'55" for recording, a time considered sufficient for the following data elaboration phase. In some of the modal nodes the acceleration sensors were arranged in bi or tri-axial configuration, while in other positions they were employed to measure unidirectional accelerations. A similar acquisition layout was repeated in the 2015 acquisition campaign.

\subsection{Results of the dynamic identification}

\subsection{1 pre-works identification results}

The signal-processing phase consisted in the elaboration of the measured data using dedicated software for OMA (Operational Modal Analysis) [5, 6, 7]. It was decided to use three frequency-domain modal parameter extraction techniques: FDD - Frequency Domain Decomposition, EFDD - Enhanced Frequency Domain Decomposition and pLSCF - poly-reference Least Squares Complex Frequency-domain.

The FDD method [8], that estimates the modes using a Singular Value Decomposition (SVD) of each of the spectral density matrices, was improved with the Enhanced Frequency Domain Decomposition (EFDD) technique. Concerning this method, the damping ratios are calculated by the application of the inverse FFT to the spectral bell associated at a certain mode shape.

The poly-reference Least Square Complex Frequency domain (p-LSCF), also known by its commercial name PolyMax (LMS) is a recent parametric frequency domain technique, firstly developed as an input-output method to perform the identification of modal parameters from FRFs [9]. However, for a system excited by white noise, there are some similarities between the modal decomposition of a FRF and of the half-spectrum. Thus, the technique was extended to an output-only version.

The data series acquired at 100 SPS were processed by a decimation of 2 (Nyquist frequency of $25 \mathrm{~Hz}$ ), with segment length of 2048 points and $66.67 \%$ window overlap. Peaks in the frequency domain related to structural frequencies were selected, and the corresponding mode shapes defined. Modal parameters were identified quite clearly, except for some inconsistencies found in the mode shapes of the highest identified modes.

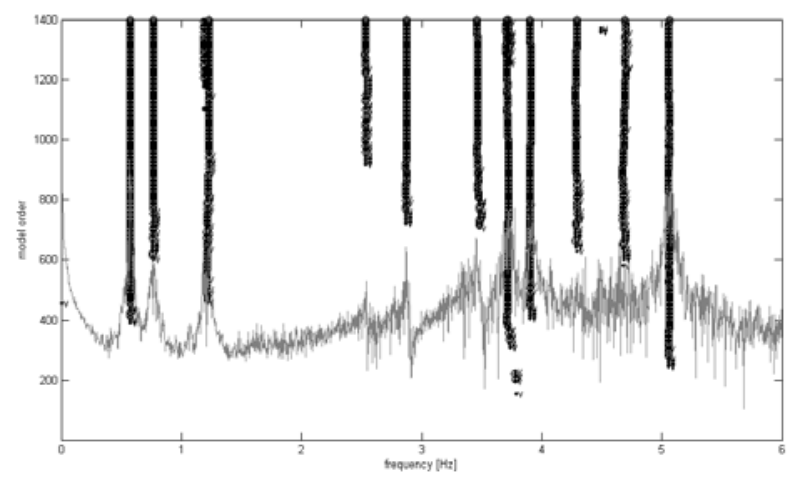

Figure 11. pLSCF method: stabilization diagram 
Table 3. Modal parameters estimation by the application of various frequency-domain identification techniques

\begin{tabular}{|c|c|c|c|c|c|c|c|}
\hline & \multirow{2}{*}{$\begin{array}{l}\text { FDD } \\
\text { Freq. } \\
{[\mathrm{Hz}]}\end{array}$} & \multicolumn{2}{|c|}{ EFDD } & \multicolumn{2}{|c|}{ pLSCF } & \multirow{2}{*}{$\begin{array}{l}\text { MAC } \\
\text { EFDD- } \\
\text { pLSCF }\end{array}$} & \multirow[b]{2}{*}{ Comment } \\
\hline & & $\begin{array}{l}\text { Freq. } \\
{[\mathrm{Hz}]}\end{array}$ & $\begin{array}{c}\xi \\
{[\%]}\end{array}$ & $\begin{array}{l}\text { Freq. } \\
{[\mathrm{Hz}]}\end{array}$ & $\begin{array}{c}\xi \\
{[\%]}\end{array}$ & & \\
\hline 1 & 0.55 & 0.57 & 1.82 & 0.56 & 1.11 & 0.99 & $\begin{array}{l}\text { Lateral } \\
\text { bending }\end{array}$ \\
\hline 2 & 0.76 & 0.76 & 1.84 & 0.75 & 1.57 & 0.97 & $\begin{array}{l}\text { Bending on } \\
\text { rear legs }\end{array}$ \\
\hline 3 & 1.15 & 1.16 & 2.05 & 1.17 & 1.84 & 0.98 & $\begin{array}{l}\text { Bending of } \\
\text { rear part }\end{array}$ \\
\hline 4 & 2.53 & 2.52 & 0.68 & 2.51 & 1.15 & 0.75 & Torsion \\
\hline 5 & 2.87 & 2.94 & 0.71 & 2.87 & 0.87 & 0.98 & Shrugging \\
\hline 6 & 3.71 & 3.74 & 1.55 & 3.72 & 1.37 & 0.77 & Swaying \\
\hline 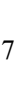 & 3.92 & 3.89 & 2.03 & 3.92 & 0.83 & 0.97 & $\begin{array}{l}\text { Antiphase } \\
\text { bending of } \\
\text { front legs }\end{array}$ \\
\hline & 5.07 & 5.07 & 0.95 & 5.06 & 0.82 & 0.97 & $\begin{array}{l}\text { Antiphase } \\
\text { bending of } \\
\text { all legs }\end{array}$ \\
\hline
\end{tabular}


MODE III $-1.16 \mathrm{~Hz}$

MODE IV $-2.52 \mathrm{~Hz}$

MODE V $-2.87 \mathrm{~Hz}$
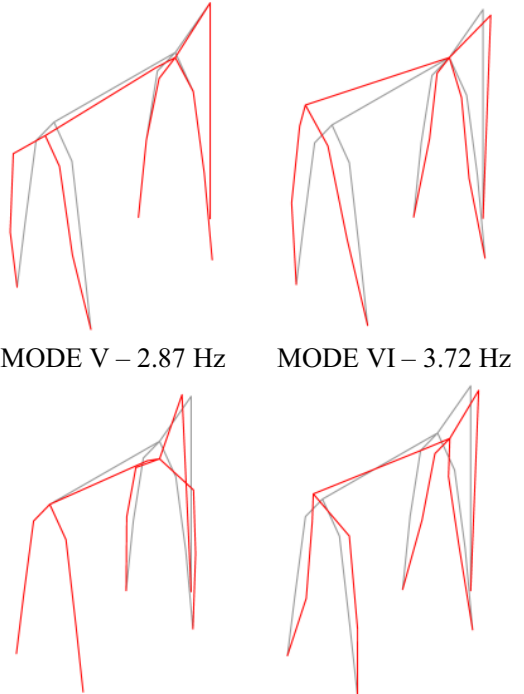

MODE VI - 3.72 Hz

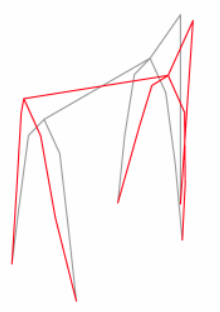

MODE VII - $3.92 \mathrm{~Hz}$

MODE VIII - $5.06 \mathrm{~Hz}$
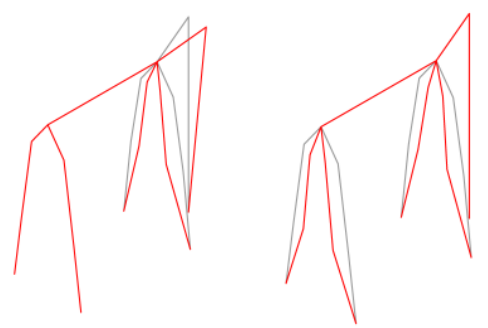

Figure 12. Mode shapes identified for the first eight natural frequencies of the mammoth

\subsubsection{Post-interventions identification results}

After the restoration interventions, it was performed a second dynamic identification campaign in order to estimate any changes in the structural behaviour of the mammoth's frame. Table 4 shows the modal parameters identified after restoration. It can be noted a slight increase in some frequencies mainly due to the different posture in which it was placed the skeleton and the different restraint conditions of the frame.
Table 4. Modal parameters estimation by the application of various frequency-domain identification techniques

\begin{tabular}{|c|c|c|c|c|c|c|c|}
\hline & \multirow{2}{*}{$\begin{array}{l}\text { FDD } \\
\text { Freq. } \\
{[\mathrm{Hz}]}\end{array}$} & \multicolumn{2}{|c|}{ EFDD } & \multicolumn{2}{|c|}{ pLSCF } & \multirow{2}{*}{$\begin{array}{c}\text { Var. } \\
\text { pre vs } \\
\text { post } \\
{[\%]}\end{array}$} & \multirow[b]{2}{*}{ Comment } \\
\hline & & $\begin{array}{l}\text { Freq. } \\
{[\mathrm{Hz}]}\end{array}$ & $\begin{array}{c}\xi \\
{[\%]}\end{array}$ & $\begin{array}{l}\text { Freq. } \\
{[\mathrm{Hz}]}\end{array}$ & $\xi[\%]$ & & \\
\hline 1 & 0.61 & 0.62 & 3.06 & 0.62 & 0.64 & $11 \%$ & $\begin{array}{c}\text { Lateral } \\
\text { bending }\end{array}$ \\
\hline 2 & 0.73 & 0.73 & 3.04 & 0.72 & 5.26 & $-3 \%$ & $\begin{array}{l}\text { Bending on } \\
\text { rear legs }\end{array}$ \\
\hline 3 & 1.32 & 1.32 & 0 & & & $15 \%$ & $\begin{array}{c}\text { Bending of } \\
\text { rear part }\end{array}$ \\
\hline 4 & 2.61 & 2.61 & 0.80 & & & $3 \%$ & Torsion \\
\hline 5 & 2.95 & 2.94 & 0.48 & 2.97 & 0.26 & $3 \%$ & Shrugging \\
\hline & & & & & & & \\
\hline 8 & 5.22 & 5.23 & 0.98 & 5.26 & 0.57 & $3 \%$ & $\begin{array}{l}\text { Antiphase } \\
\text { bending of } \\
\text { all legs }\end{array}$ \\
\hline
\end{tabular}

\section{Proposal for the seismic isolation of the mammoth}

The engineering activities carried out in parallel with the restoration of the mammoth skeleton were able to identify the static and seismic behaviour of the supporting structure, underlining its capacity to survive a relevant earthquake, however paying the toll of relevant displacements, which induced undesirable effects with respect to the conservation issues.

A proposal for the substitution of the frame, with base seismic isolation was then suggested, but it was not realized for lack of funds. Only minor modifications were finally introduced in the original structure, mainly for paleontological "postural" reasons (elongation of the spine, enlargement of the legs), and the FE model of the final configuration, together with the re-execution of the experimental activities, indicated that the structural response of the mammoth supporting structure, after the restoration, is basically the same as before.

\subsection{FE simulation of the seismic isolation}

The original model of the supporting frame was used, simulating the presence of the bones as point mass applied to the FE structure in the exact position of connection between bones and frame. The analyses were then re-run and the static and dynamic pattern of the fully 3D and simplified models were compared, indicating that the simplification did not excessively alter the structural features of the original model.

The frame model was then stiffened at the base by means of a grid of HEB200 steel girders, and a complete fixed connection was provided between these and the original supporting structure, which was not modified (Figure 13). As supports, using a simplified approach, linear springs were introduced below the base steel frame in the XY directions - simulating the isolation devices and vertical fixed supports for the $\mathrm{Z}$ direction. Considered the different mass localization of the model, stiffer springs were located below the pole supporting the skull, in order to regularize the dynamic features of the isolated system (i.e. to avoid torsional modes). The 
reduced stiffness values of 50 and $28 \mathrm{~N} / \mathrm{cm}$ were employed for the front and rear springs respectively.

The modal analysis and the seismic response analysis were re-executed on the base isolated model, by considering the same seismic input as above (AQU station recorded spectrum), without any spectral damping increase due to the isolation devices. Results in terms of eigenvalues (natural frequency analysis) are reported in Table 5. From the obtained results it is possible to observe the effects of the isolation in terms of frequency shift (from a period of approximately $2 \mathrm{~s}$. for the first frequency of the original structure to a period of $3 \mathrm{~s}$. for the first and second frequencies of the base isolated structure). A more important result corresponds to the displacement pattern for the isolated model, with respect to the original one. As it is possible to appreciate from Figure 14, the comparative plot of the seismic XYZ displacements clearly indicates that the relevant relative displacements between the base and the top of the frame in case of the original structure (more than $0,2 \mathrm{~m}$ ) are strongly reduced in the isolated structure simulation $(0,03$ $\mathrm{m})$, acting almost as a rigid body with approximately the totality of the participating mass in the first two modes, respectively in the transverse and longitudinal directions.

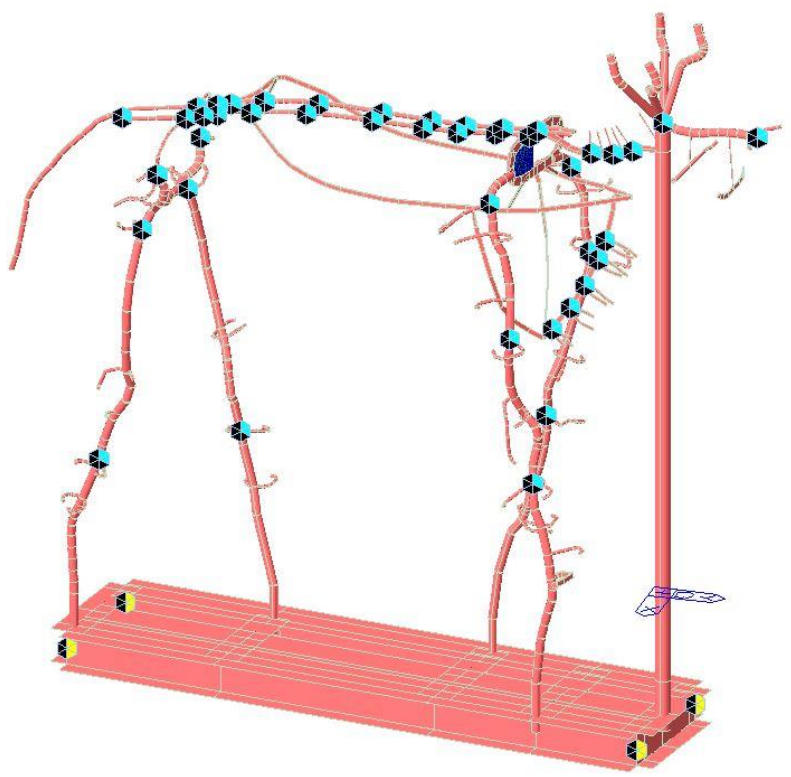

Figure 13. frame model with application of nodal masses and base isolation

Table 5. FE model eigenvalues, natural frequency analysis, original (above, grey) and base isolated (below) models

\begin{tabular}{|c|c|c|c|}
\hline Mode nr. & $\begin{array}{c}\text { Frequency } \\
(\mathbf{H z})\end{array}$ & $\begin{array}{c}\text { Mass X } \\
(\mathbf{\%})\end{array}$ & $\begin{array}{c}\text { Mass Y } \\
(\mathbf{\%})\end{array}$ \\
\hline $1^{\text {st }}$ mode & 0.534 & 77.35 & 4.13 \\
\hline $2^{\text {nd }}$ mode & 0.624 & 11,07 & 69.34 \\
\hline $1^{\text {st }}$ mode & 0.331 & 94.57 & 4.82 \\
\hline $2^{\text {nd }}$ mode & 0.332 & 4.94 & 94.39 \\
\hline
\end{tabular}
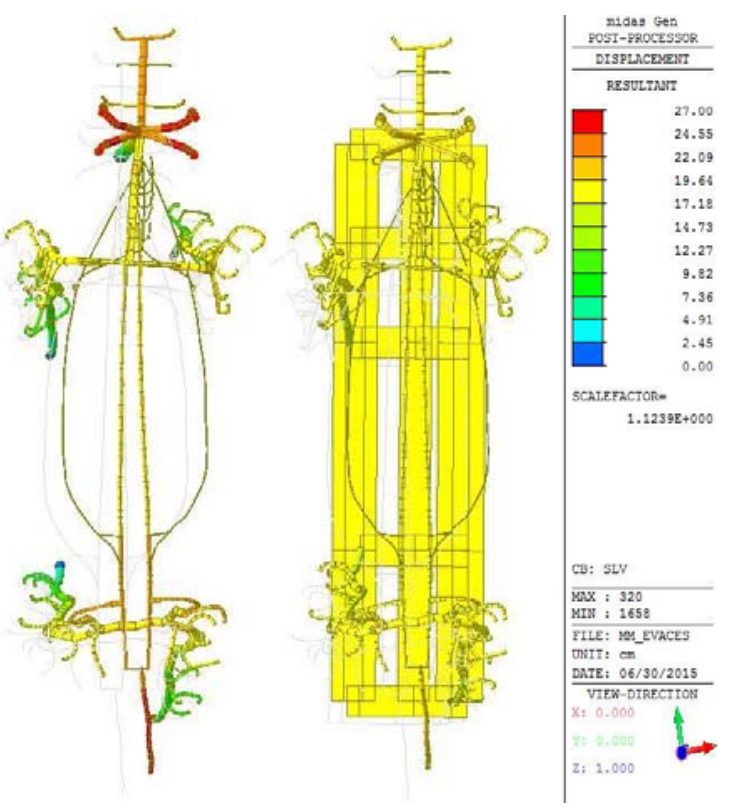

Figure 14. seismic XYZ displacements: a) original and b) base isolated structure

\section{Conclusions}

In the field of restoration a multidisciplinary approach is considered more and more essential for acquiring a satisfactory knowledge level of the different aspects from both humanistic and technical point of view related to the conscious conservation of existing relevant goods. In this case, being this one of the first applications ever, a mammoth fossil was restored by using the conservation principles commonly employed in the field of the architecture.

Since the location of the mammoth was L'Aquila, recently struck by a strong earthquake causing severe damage, the engineering stability aspects played a very relevant role, and it was then possible to study in detail the structural features of the frame supporting the bones.

From the studies carried out, both considering numerical simulations and experimental activities it emerged the peculiar structural feature which "saved" the mammoth from the earthquake, namely the high deformability of the metallic frame, strongly reducing the structural stiffness and hence avoiding the mammoth to "enter" in the most energetic spectral area of the 2009 earthquake. However, high differential displacements were attained during the seismic motions, and this caused damage to the vulnerable bones of the mammoth.

The dynamic identification - carried out before and after the restoration interventions - and relying on Output Only Techniques was effectively employed to calibrate a very complex FE models, used for the structural analysis.

A proposal was finally made towards the seismic isolation - currently a topic of great interest for valuable goods in museums in seismic prone areas [10] - of the mammoth, showing the beneficial effects of this technique also in order to comply with the Damage (or Artistic) Limit State. 


\section{References}

1. http://www.mammuthusmuseo.com/

2. midas FEA 2013 ver . 1.1 - MIDAS

3. M. Çelebi, P. Bazzurro, L. Chiaraluce, P. Clemente, L. Decanini, A. DeSortis, W. Ellsworth, A. Gorini, E. Kalkan, S. Marcucci, G. Milana, F. Mollaioli, M. Olivieri, R. Paolucci, D. Rinaldis, A. Rovelli, F. Sabetta, C. Stephens, Recorded Motions of the 6 April 2009 Mw 6.3 L'Aquila, Italy, Earthquake and Implications for Building Structural Damage: Overview, Earthquake Spectra, Volume 26, No. 3, pages 651-684, August 2010; (C) 2010, Earthquake Engineering Research Institute

4. Italian Technical Standard for Constructions - NTC 2008 - Ministerial Decree Jan.14 2008

5. SVS ARTeMIS Extractor 4.0, 2007

6. MACEC ver. 3.2, 2011

7. E. Reynders, M. Schevenels, G. De Roeck, MACEC 3.2: A Matlab toolbox for experimental and operational modal analysis. Technical Report bwm2011-01, Department of Civil Engineering, K.U.Leuven (2011)

8. R. Brincker, L. Zhang, P. Andersen, Modal identification from ambient responses using frequency domain decomposition, in Proceedings of the IMAC 18, International Modal Analysis Conference, San Antonio, USA (2000)

9. B. Peeters, H. Van der Auweraer, POLYMAX: a revolution in operational modal analysis, Proc. 1st International Operational Modal Analysis Conference (IOMAC), in IOMAC 2005, Brincker \& Moller (eds.), Copenhagen, Denmark, pp. 41-51 (2005)

10. G. De Canio, Marble devices for the Base isolation of the two Bronzes of Riace: a proposal for the David of Michelangelo, proc. 15 WCEE Lisbon, Portugal (2012) 